\title{
Analysis of Uplift Force of Steel-Concrete Composite Beams Under Negative Moment
}

\author{
Wenyuan Liao, a, Dewen Liu, b, Bihui Dai ${ }^{1, c}$ \\ ${ }^{1}$ Faculty of civil Engineering, Southwest Forestry University, Kunming 655024, China \\ alwy065@126.com, b373537671@qq.com, c2807505863@qq.com
}

Keywords: Composite Beam, Negative Moment, Stud, Uplift force, FEM, Non-linear

Abstract: In order to investigate the uplift force of composite beam under negative moment. Three composite beams were analyzed by using the finite element program ANSYS and the finite element models were established with both material and geometrical non-linearity. Specimens had the same section size and different in the connecting degree of shear connectors. The results show that the uplift force of single stud was increases with the increasing of distance between studs. The distribution of uplift force of studs along the beam length were acquired and provided a numerical basis for interface study considering the surface slip and vertical uplift effects of continuous composite beam.

\section{Introduction}

According to the related specifications[1,2], composite beam should be complete shear connection design in the negative moment regions of continuous composite beams, but experimental and theoretical study [3,4] shows that, even in the full shear connection design of composite beams under negative moment, the stud based flexible shear connectors can also occur shear deformation and axial deformation, so that the horizontal slip and vertical uplift in the concrete and steel beam flange interface could appeared. The paper aims to investigate the uplift force of studs along the composite beams. The finite element model is established by ANSYS to predict the mechanical properties of them.

\section{Size of specimens}

Combined with the engineering practice and consideration of the construction convenience, the sizes of composite beams are shown in Fig.1. Three specimens with same section size and span are designed. The numbers of shear connectors in three specimens are different(see Table.1).

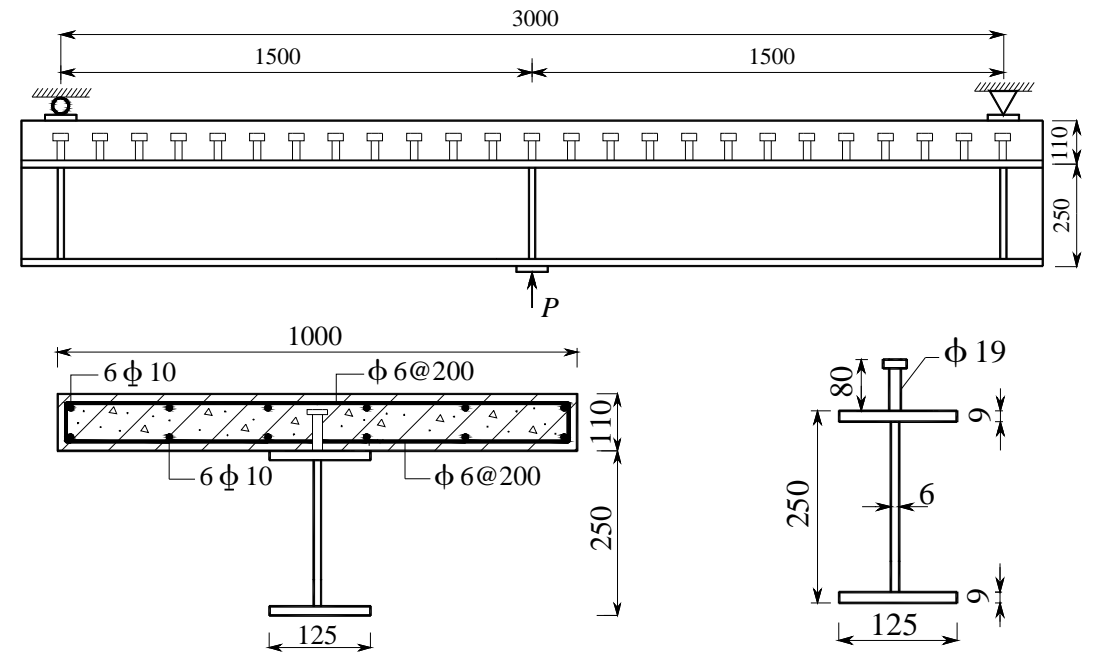

Fig.1 Geometrical sizes of specimen CB-1 CB-3 
Table.1 Shear values of opening section

\begin{tabular}{|c|c|c|c|}
\hline Specimen number & CB1 & CB2 & CB3 \\
\hline Number of stud & 31 & 21 & 11 \\
\hline
\end{tabular}

\section{Finite Element Modeling}

Element types and material properties. Element types are shown in Fig.2. Solid45 for flanges, Plane42 for web, Shell43 for stiffeners, Solid65 for concrete slab, Link8 for steel bar, Beam44 for stud and use Combin39 to simulate slip deformation. Bilinear isotropic hardening rule is used for steel material together with the Von-Mises yield criteria and the constitutive relation uses the ideal elastoplastic mode (see Fig.3), $\mathrm{f}_{\mathrm{y}}=235 \mathrm{MPa} ; \mathrm{E}_{\mathrm{s}}=2.06 \times 10^{5} \mathrm{MPa}$; Poisson's ratio is 0.3 . Multiple linear isotropic hardening rule is used for concrete together with the Willan-Warnke five-parameter failure criterion and the constitutive relation uses the Hognestad stress - strain curves(see Fig.4), $\mathrm{f}_{\mathrm{c}}=19.1 \mathrm{Mp} ; \mathrm{E}_{\mathrm{c}}=3.25 \times 10^{4} \mathrm{Mpa}$; Poisson's ratio is $0.2 ; \varepsilon_{0}=0.002, \varepsilon_{\mathrm{u}}=0.0038$. Stress - strain curves of stud are shown in Fig.6.

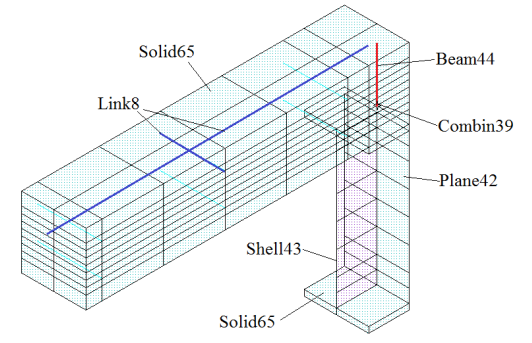

Fig.2 Element types

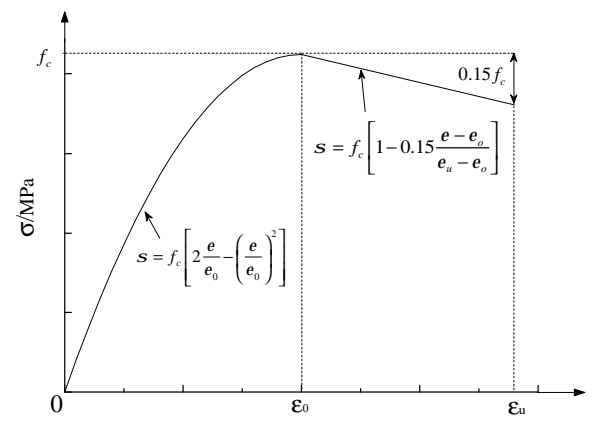

Fig.4 Stress-strain model of concrete

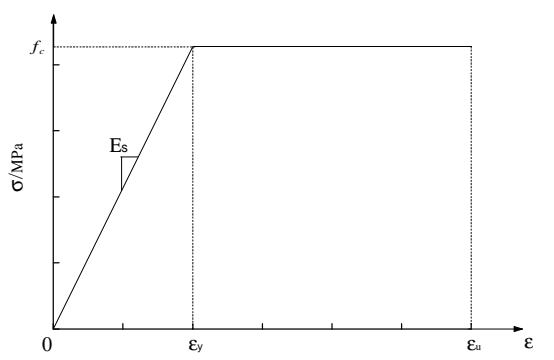

Fig.3 Stress-strain model of steel

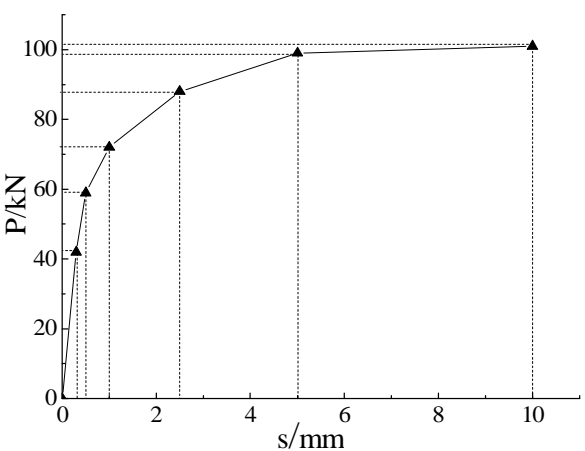

Fig.5 Load-slip model of stud

Due to the structural symmetry, it is more effective modeling specimen by $1 / 2$ model structure. Elements mesh refining near the opening can improve the accuracy of calculation. Finite element model is shown in Fig.6.

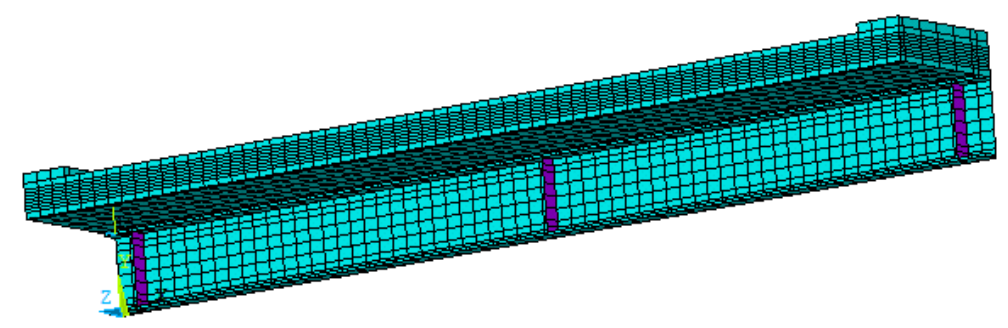

Fig.6 Finite element model

\section{Analysis of calculation results}

Moment-deflection curves of composite beams. The Moment-deflection curves are shown in Fig.7, the uplift force of studs are shown in Table 1. 


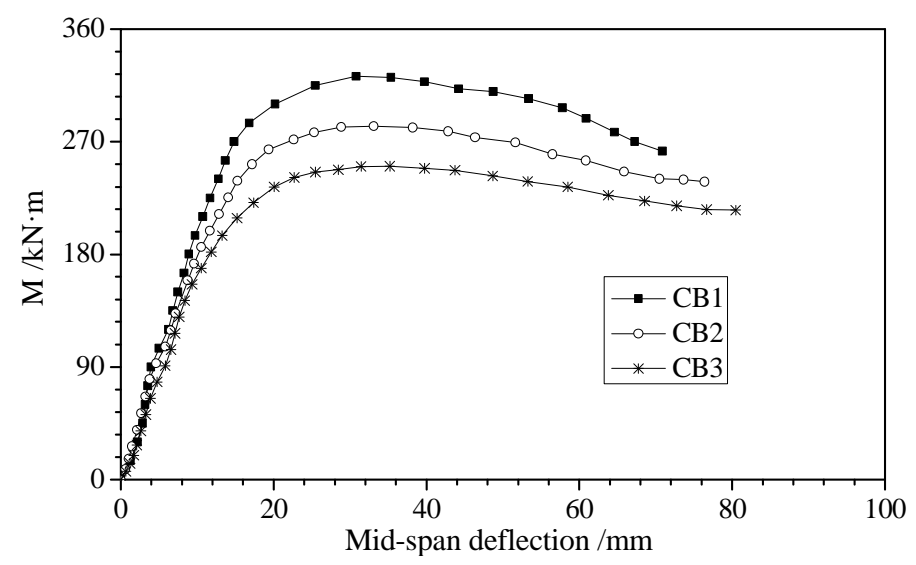

Fig.8 Moment-deflection curves of specimens

As can be noted from Fig.8, three specimens have the same failure mode and the moment-deflection curves can be divided into three stages: elastic stage, elastic-plastic stage and plastic stage. In elastic stage, curve is linear; the first turning is emerged in elastic-plastic stage. CB1 has the largest ultimate bending moment because it has the largest connecting degree of shear connectors. However, the deflection of CB1 is the minimum. It is shown, with the decrease of the connection degree, the ultimate flexural capacity is reduced, but the deflection value has increased, which indicated the improvement of the ductility.

Uplift force of studs. The distribution of uplift force is shown in Fig.9.

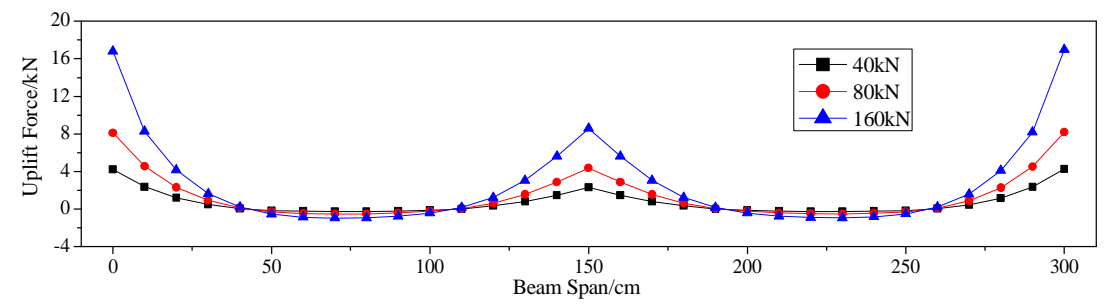

(a) CB1

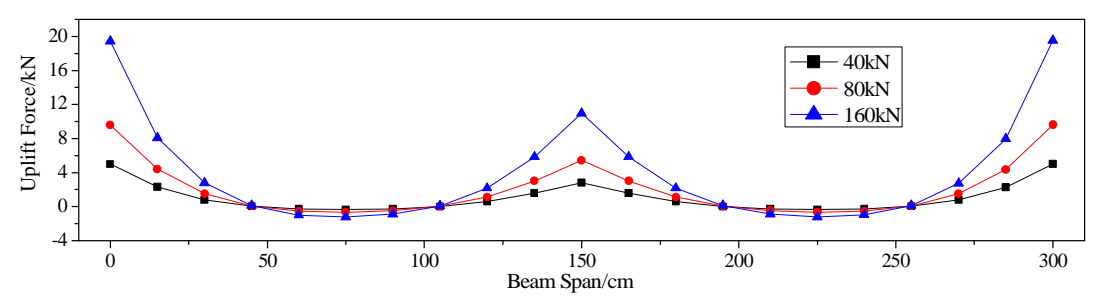

(b) $\mathrm{CB} 2$

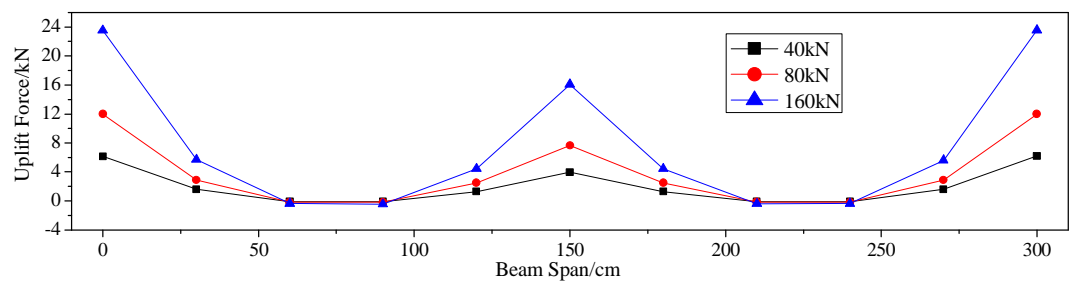

(c) $\mathrm{CB} 3$

Fig.9 Distribution of uplift force

It can be seen from Fig.9, the distribution of uplift force of all specimens has the same variation law. Take the example of CB1, the main bearing of studs is tension and stud near the support has the maximum value of uplift force. CB1 has 31 studs, compared with CB2 and CB3 which has 21 and 11 studs the value of uplift force of individual stud is relatively small. This indicated the value of uplift force is relatively small in composite beam with larger connecting degree of shear connectors. 
Take the example of CB3, it has only 11 studs in CB3, so the distance between studs are relatively large, which lead to greater value of uplift force of individual stud. The value of uplift force of individual stud is increase with the increase of the stud spacing and the value of uplift force of individual stud is decrease with the decrease of the stud spacing.

\section{Conclusions}

This paper aims to investigate the uplift force of composite beam under negative moment. The FEA model developed in this paper can reliably predict the distribution of uplift force of steel-concrete composite beams under negative moment. The distribution of uplift force are shown in Fig.9, which indicated that the value of uplift force of individual stud is increase with the increase of the stud spacing.

\section{Acknowledgements}

This work was financially supported by Yunnan Applied Basic Research Projects(217014), Yunnan Provincial Department of Education Science Research Fund Project(51700211).

\section{References}

[1] AISC-LRFD, Load and resistance factor design specification for steel structural buildings [S].Chicago: American Institute of Steel Construction Inc, 1999.

[2] ENV 1994. Eurocode 4: Design of composite steel and concrete structures [S]. London, British Standards Institution, 1994.

[3] Faella C., Martinelli E., Nigro E. Shear connection nonlinearity and deflections of steel-concrete composite beams: a simplified method. Journal of Structural Engineering, 2003, 129(1):12-20.

[4] Gaetano Manfredi, Giovanni Fabbrocino, Edoardo Cosenza. Modeling of steel-concrete composite beams under negative bending[J]. Journal of EngineeringMechanics, 1999, 125(6): 654-662. 